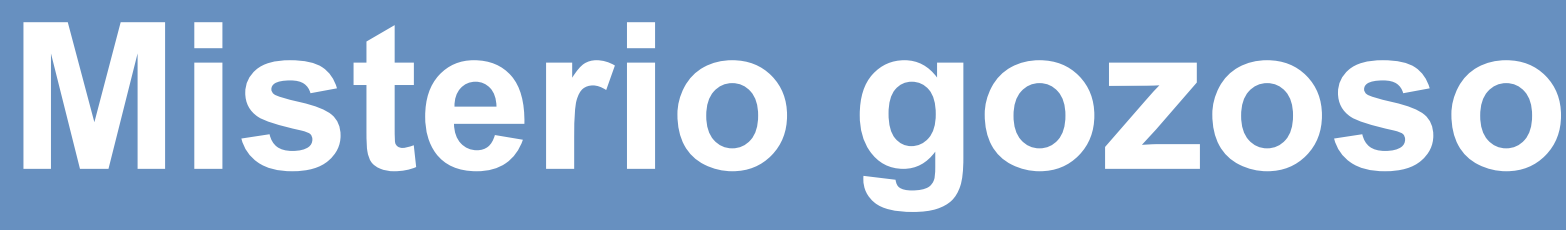

\title{
Reflexiones sobre la
} relación arte-emoción

\section{Abdel Aloysius Aguirre Porras}

Universidad Iberoamericana Ciudad de México

Joyful Mystery

Thoughts on the Art-Emotion Relationship

Recepción: 5 de septiembre de 2021

Aceptación: 28 de septiembre de 2021 
¿Has llorado ante a una obra de arte? Personalmente debo admitir que he derramado una que otra lágrima con películas, canciones o libros que me han conmovido. Pero también he tenido respuestas más difíciles de describir con palabras. Como aquella vez en el museo de San Carlos cuando, doblando la esquina en uno de sus pasillos, me encontré de frente con "La demencia de Isabel de Portugal" de Pelegrín Clavé, o más bien, me encontré con su mirada. Tanta fue la impresión, que recordando la pintura sólo podía rescatar de mi memoria la expresión de esos ojos levemente oscurecidos por el velo de la reina. Había olvidado a sus hijos suplicantes y el desconcierto de las personas a su alrededor. Cuando vi aquella pintura sentí algo difícil de describir, una especie de hormigueo cálido, como una cachetada que el artista llevaba esperando darme por más de un siglo. De lo que estoy seguro es de que mi reacción tiene un trasfondo emocional, sé que hubo una tensión entre mi persona y aquella pintura que pude sentir físicamente.

El arte es como un prisma: dependiendo de la cara por donde dejemos entrar la luz, es el color que percibiremos. Una de estas caras le concierne al ámbito emocional: el arte, sin duda, tiene el potencial para despertar una amplia gama de emociones. Nos puede llevar al enojo y a la indignación, como el impacto causado por Olympia de Manet o Who's Afraid of Red, Yellow and Blue III de Newman (esta última, una obra que ha sido víctima de vandalismo). También nos puede llevar al llanto o a reacciones más difíciles de describir, sólo recordemos el famoso síndrome de Stendhal, un fenómeno que ocurre cuando, confrontadas ante grandes obras de arte, las personas experimentan palpitaciones aceleradas, dolor de pecho y sudoración, como si el cuerpo entrara en un estado de shock estético al no saber cómo reaccionar ante tales impactos. La emoción involucra al cuerpo, la emoción es cuerpo. Recuerda frases como "un nudo en la garganta" o "se me estrujó el corazón", son metáforas cotidianas que usa- 
mos para dar sentido a esas sensaciones físicas que aparecen en nosotros y que dotan de significado lo que estamos viviendo. Podemos concebir a nuestro cerebro como una constante tormenta de químicos y electricidad disparada por acontecimientos internos (por ejemplo, un recuerdo) o externos (como el que abordo en este ensayo: el arte); somos capaces de sentir directa y personalmente los efectos de dichos procesos biológicos, para luego etiquetarlos, los nombramos para poder reconocerlos. Estos procesos inician en nuestro cuerpo para luego pasar por la lente de nuestro ser, de nuestra experiencia; de esta manera los transformamos en algo más, los elevamos sobre los simples procesos físicos, establecemos una relación entre la emoción y lo que la ocasiona.

Así, entre el arte y la emoción se construye una frontera que separa a ambas, pero a pesar de definir una división, esta frontera es, a su vez, delgada y porosa. Un ejemplo claro de la fluidez de esta relación puede verse en el trabajo de David Freedberg, historiador del arte que se ha dado a la tarea de estudiar las respuestas de nuestro cerebro al entrar en contacto con los estímulos del arte, tratando de establecer una relación entre la obra (con un énfasis en lo visual) y los procesos neuronales que éstas desatan en nosotros. Pero ¿es esto suficiente? Si estoy consciente de que se activa cierta red de neuronas en mí que dan como resultado una respuesta empática ante lo que estoy viendo en una pintura, ¿entenderé mejor mis emociones? ¿Podré solucionar el misterio de este cuarto cerrado en el que se transforma mi cuerpo?

Estos esfuerzos por comprender de una manera más objetiva claramente nos dan un mejor entendimiento de algunos de los mecanismos internos que operan cuando, por ejemplo, observamos una pintura; además de que abren un área de estudio y levantan una serie de preguntas importantes dignas de formularse y que amplían nuestro conocimiento del arte. Aun así, no considero que tengan la última palabra o sean, realmente, el punto final de la conversación: lo cierto es que son una pieza del rompecabezas 
Mientras tanto, del otro lado de la frontera tenemos un elemento menos sólido: el de nuestra experiencia, entendida como el sentido que le damos al remolino de emociones dentro de nosotros. Este elemento realmente presenta un aspecto que pareciera inasible en nuestra experiencia artística, ese momento en que una canción o una pintura nos alegra el día o nos conmueve. ¿Lloro sólo porque mis neuronas fueron estimuladas o por algo más?

El historiador James Elkins se dio a la tarea de tratar de encontrar la respuesta a este misterio, centrándose específicamente en el llanto. Del resultado de su investigación surge un libro hermoso titulado Picture and Tears. En dicho trabajo, para encontrar la respuesta que buscaba Elkins no hizo escaneos cerebrales, sino que preguntó directamente a las personas si habían llorado o no frente a alguna pintura y por qué creen que había desencadenado dicha reacción. En su exploración, Elkins llega a tres causas del llanto, pero considero que estas respuestas no son realmente lo más importante de su investigación, sino las respuestas en bruto dadas por los participantes. Como aquella mujer que lloró frente a la Victoria de Samotracia y expresó "No tenía brazos, pero era tan alta". ${ }^{1}$ Así describió su experiencia ante la escultura y la razón de su llanto. Las palabras claramente le fallan y nos deja sólo con un acertijo gramatical o un enigma que poco nos dice si queremos entender con exactitud su experiencia, pero mucho si la tomamos como se nos presenta: confusa, intensa, difícil de aprehender, real. Tratar de entender por completo experiencias como ésta (ya sea que lo hagamos histórica, química o biológicamente) puede adormecernos ante la riqueza de la experiencia misma.

Pero no quisiera implicar algo que no es mi intención. No digo que el estudio de la relación arte-emoción en sus diversas aristas sea innecesario, al contrario, nos es útil para ir dotando de sentido a este fenómeno. Sin embargo, también es importante sólo dejar que acontezca en nosotros el llanto, la alegría, la melancolía, la repulsión o cualquier otro sentimiento que experi-

1 Elkins, Pictures and Tears, 21. 
mentemos. El filósofo John Dewey² consideraba a las emociones como parte clave de la experiencia artística. Para él, una experiencia es algo completo, con inicio y fin, mientras que la emoción es el elemento que la unifica, que le da unidad. ¿Por qué recuerdo con tanta claridad la mirada de Isabel de Portugal en aquella pintura? ¿Por qué puedo rescatar de mi memoria con tanto detalle el momento exacto en el que vi el performance "The Lovers" de Marina Abramović? Claramente algo removieron en mí, la tristeza y la sorpresa anclaron las obras en mi mente, porque no solamente las vi, sino que las experimenté, me involucraron en el pequeño mundo que lograron crear.

La emoción no es entonces un elemento incidental ni un accidente. Cuando hablamos del arte, incluso se puede afirmar que éste se perfila como un elemento esencial, porque hasta la indiferencia, la ausencia de emociones, nos sigue comunicando algo sobre quien lo vive. Porque entrar en contacto con el arte va más allá de "entenderlo", de comprender la composición pictórica, el uso del color o su materialidad; entrar en contacto con el arte implica un choque de experiencias que parecieran aisladas, pero que se unen en una sola. Podemos ahondar en este secreto y develar el enigma, pero también podemos simplemente sentir. Nuestras neuronas se pueden estimular al ver el sufrimiento retratado en "La balsa de la Medusa" de Geéricault o al ver a Judith decapitando a Holofernes en la pintura de Gentileschi, podemos establecer una relación clara entre estas obras y la activación de nuestros lóbulos cerebrales, pero también podemos vivir la emoción. Podemos gozarlo. Esto también es entender el arte y establecer una relación profunda y rica con él. Experimentar una emoción siempre tendrá un carácter profundamente personal: sólo nosotros sabemos cómo la estamos sintiendo, para los demás mantiene un halo de misterio.

Lo anterior nos lleva a la conclusión de que el arte no sólo puede experimentarse intelectualmente. Tal vez nunca podamos encontrar la respuesta a la pregunta sobre la naturaleza exacta de la relación entre el arte y las

2 Dewey, El arte como experiencia, 48-49. 
emociones, pero sí podemos dar con una respuesta: nuestra respuesta, sin preocuparnos sobre su universalidad o que otros entiendan con exactitud lo que estamos viviendo. Hay que dejar que el arte y la emoción se enfrenten, que se nos presenten como la experiencia total que son, como cuando das la vuelta en el pasillo de un museo y, casi por accidente, te encuentras en una sala solitaria y ante ti aparecen unos ojos intensos, levemente oscurecidos por un velo, y en tu interior ocurre algo que no comprendes del todo, que no puedes explicar con claridad, cuya única certeza es que existe y lo estás sintiendo. Dejemos que el arte se manifieste ante nosotros y que seamos el puente vivo de la relación arte-emoción. Hagamos preguntas a nuestro cuerpo y a la obra en cuestión, indaguemos hacia dentro y hacia fuera, tal vez así descubramos un poco más de lo que se esconde detrás de esta cortina, aunque al final la exploración termine en un descubrimiento personal, íntimo o difícil de aprehender. Hay que otorgar al arte la oportunidad de ser un misterio gozoso digno de ser vivido.

\title{
Bibliografía
}

Dewey, John. El arte como experiencia. Barcelona: Paidós, 2008.

Elkins, James. Picture and Tears: A History of People Who Have Cried in Front of Paintings. Nueva York: Routledge, 2004.

\author{
Abdel Aloysius Aguirre Porras \\ Psicólogo por la Universidad del Valle de México, se ha desempeñado \\ como profesor en los niveles de secundaria y preparatoria. Posteriormente \\ estudió la maestría en Estudios del Arte dentro de la línea de investigación \\ de Arte y Educación en la Universidad Iberoamericana, donde como pro- \\ yecto de tesis diseñó y aplicó un taller de cómic para el desarrollo de habi- \\ lidades socio-emocionales en niños.
}

